\title{
Un arte con machete. Comentario sobre la obra de flonso Jiménez
}

\author{
Miguel Gutiérrez-Peláez* \\ Universidad del Rosario, Bogotá, Colombia.
}

Con Alonso Jiménez hemos podido conversar sobre la anécdota que trae Umberto Eco a propósito del retrato que le realiza Pablo Picasso a la poeta estadunidense Gertrude Stein. Terminando el retrato, un observador lo increpa y le dice: "Pero no se parece", a lo que Picasso responde: "Pero se parecerá". Hay múltiples efectos que se extraen de esta anécdota. Por un lado, el más evidente, es que nadie se acordará de cómo era Gertude Stein, pero todos podremos tener clara la imagen del retrato que hizo de ella Picasso. Por lo tanto, el rostro de Stein que pasa a la posteridad es el de Picasso y no el suyo. Otra consecuencia que puede extraerse es que en ese cuadro de Picasso se revela una dimensión de Gertrude Stein que es esquiva a la cámara y al espejo y que requiere el trazo del pintor para poder aflorar. Hace un par de años, tuve la fortuna de que Alonso Jiménez se animara a hacerme un retrato. Cuando me lo entregó, me dijo "no sé si se parece, pero eso fue lo que me surgió". Al verlo, tampoco yo sabía si me parecía. Esa noche llegué a mi casa y puse el cuadro en el suelo, contra una pared de la sala. Mi hijo, de entonces un año y medio y que apenas poblaba su mundo del lenguaje con un repertorio reducido de palabras, se acercó al cuadro, lo miró y dijo: "otro papá".

Tal vez haya alguna relación entre la mirada artística de Alonso Jiménez y la del niño. No en vano tituló una exposición reciente de su obra: Idea perdida de un niño. Veo en la obra de Alonso un interés por la mirada infantil, como si se reeditara cierta idea de los ojos de los niños como dotados de una visión privilegiada, que pueden ver los fenómenos con una transparencia y una ausencia de contaminación propia de la mirada del adulto. Algo, efectivamente, de ese retrato que realiza Alonso logra transmitir una dimensión de mi ser oculta aun para mí mismo, pero que en la mirada incontaminada de mi hijo es una obviedad. Tienta incluso a traer una tesis de un colega de Freud, Carl Gustav Jung, quien partió de los postulados freudianos para luego distanciarse y adentrarse en una lectura mística del inconsciente, sumergiéndose en estudios sobre alquimia y metafísica. Jung elabora su propia idea del inconsciente como aquel receptáculo en todo psiquismo humano que se conecta con la ontogenia y filogenia de la especie. Así, cada hombre, en su inconsciente, es todos los hombres: cada uno de los seres que han poblado la faz de la tierra. El niño del año 2016, oculto bajo sus cobijas, con miedo a la oscuridad, es el hombre primitivo que sabe que, en ausencia del fuego, es presa fácil para los depredadores feroces. Hay algo de la obra de Alonso Jiménez que parece conectarse con lo más primitivo y ancestral de lo humano. Su obra no solo está en contigüidad con el arte de su tiempo, sino también con esos primeros trazos de nuestros antepasados en las paredes interiores

* Profesor del Programa de Psicología de la Universidad del Rosario, Escuela de Medicina y Ciencias de la Salud, GI Individuo, Familia y Sociedad, Bogotá, Colombia. 
de las cavernas, trazos que intentaban grabar un surco que trajera a nuestro mundo una impresión de lo imposible, de lo real. Los rostros quiméricos que pueblan la obra de Alonso Jiménez parecen hacer presente lo que se sugiere como impresiones anteriores al fenómeno, como si se hiciera porosa la tela de la realidad y, tensándola hasta sus límites, se anticiparan los vestigios de otro mundo.

Sobre los retratos de Francis Bacon, decía Milan Kundera (2009):

Miro los retratos de Bacon y me sorprende que, pese a su “distorsión”, se parezcan todos a su modelo. Pero ¿cómo puede parecerse una imagen a un modelo del que es, conscientemente, programáticamente, una distorsión? Sin embargo, se le parece; lo prueban las fotos de las personas retratadas [...]. Si bien "en distorsión", esos retratos son fieles. De ahí mi sensación de un milagro. Estas variaciones difieren una de otra y, no obstante, no dejan de tener algo común: 'ese tesoro, esa pepita de oro, ese diamante oculto', el ‘yo' de un rostro. Podría decirlo de otra manera: los retratos de Bacon cuestionan los límites del yo. ¿Hasta qué grado de distorsión un individuo sigue siendo él mismo? ¿Hasta qué grado de distorsión un ser amado sigue siendo el mismo ser amado? ¿Durante cuánto tiempo un rostro querido que se aleja en una enfermedad, en una locura, en un odio, en la muerte, sigue siendo aún reconocible? ¿Dónde está la frontera tras la cual un "yo" deja de ser "yo"? (p. 57)

La obra de Alonso plantea una interrogación permanente a los límites del yo y una bitácora de sus exploraciones en ese no man's land en los confines de la experiencia sensible.

El psicoanálisis, desde sus inicios, se ha interesado por el arte. Por las páginas de la obra de Freud no solo circulan los nombres y obras de psicoanalistas, psicólogos y filósofos, sino también de escritores como Goethe, Shakespeare y Dostoievski, y artistas como Miguel Ángel y Leonardo Da Vinci —Ernst, uno de los hijos de Freud, fue un arquitecto vanguardista que tuvo a su cargo el diseño de las clínicas psicoanalíticas gratuitas de Viena (Danto, 2005); Ernst, a su vez, es el padre de Lucien Freud, uno de los pintores más importantes del siglo XX-. Siempre se sintió fascinado Freud, como tantos psicoanalistas posteriores, por lo que el arte y el artista pueden enseñar acerca del psiquismo humano, de su funcionamiento y sus posibilidades. Los psicoanalistas nos hemos nutrido de las múltiples, amplias y singulares enseñanzas del arte. La posición del psicoanalista no es aplicar el saber del psicoanálisis al arte.

Sin embargo, ciertos psicoanalistas en la historia del movimiento analítico se sintieron seducidos por esta idea e intentaron "psicoanalizar" salvajemente a los artistas a partir de su obra. Proponiéndoselo o no, redujeron las producciones artísticas a fenómenos patológicos y el valor estético y creador quedó reducido a un signo sintomático. La posición del psicoanálisis, por lo menos a partir de la orientación del psicoanalista francés Jacques Lacan, no es ver el psicoanálisis aplicado al arte, sino más bien el psicoanálisis implicado en el arte (Recalcati, 2006). La vuelta de tuerca es total: es el arte el que nos enseña sobre psicoanálisis y puede anticiparnos aspectos de esa dimensión humana. Cuando los psicoanalistas vemos una obra como la de Alonso Jiménez, somos analizados por la obra; esperamos de ella una interpretación, una enseñanza sobre nosotros mismos. Nos nutrimos de esa fuente inagotable. El saber, para el psicoanalista, no está solo en los libros de psicoanálisis; también en tantos otros fenómenos sociales: en las palabras que pronuncian nuestros pacientes desde el diván y en la propia experiencia que hemos hecho de nuestro inconsciente. Es eso lo que produce un agujero en el saber.

Es este el milagro del arte. ¿Cómo es posible que algo tan absolutamente singular como una obra de arte, forjada y parida desde las entrañas más remotas de un ser humano, desde ese reducto interior absolutamente esquivo al lazo social, pueda decirle y significarle algo a un otro? Los sujetos que las 
observan no solo encuentran sentidos en la obra misma, sino que la obra les puede decir también cosas de su propia historia vital y pueden encontrarse en estas producciones artísticas resonancias de momentos cruciales de nuestra propia existencia, mortal y sexuada, y de los júbilos y desdichas que la componen. ¿Cómo es posible que se haga lazo con algo tan absolutamente singular? Y, sin embargo, en momentos privilegiados, eso sucede. He ahí el milagro.

Voy a citar un autor habitualmente no citado en ámbitos académicos. Pero resulta que me topé al azar con una página del libro La importancia de morir a tiempo (2013) y me pareció que lo que allí planteaba Mario Mendoza se conectaba con mi propia lectura de la obra de Alonso Jiménez. En ese texto, titulado "El filo de la navaja", el mismo título de la novela de Somerset Maugham, Mendoza habla de la literatura y dice lo siguiente:

Creo profundamente en la peligrosidad de la literatura. Si no hay algo filoso, el libro ingresa en lo acartonado, en la comodidad, en el confort que entretiene pero que no cuestiona, ni revisa, ni se subleva. Y como escritor me angustia que la escritura me haya aislado de ese propósito, me haya recluido en mi estudio durante años y me haya impedido salir a encontrarme con los lectores a crear focos de resistencia civil que se opongan a este delirio general que poco a poco va confirmando con mayor claridad nuestra miserable condición humana.

No se trata solo de contar buenas historias, no. Eso lo puede hacer cualquiera que redacte bien y ya está. Es preciso que el escritor ingrese en realidades inéditas, que ahonde, que penetre y que agudice de tal manera su forma de percibir que los demás podamos después de leerlo modificar y reinventar el mundo que nos rodea. Y para eso es preciso que el artista esté enchufado a dimensiones curiosas de lo real, que haya vivido a fondo, que conozca los límites de la euforia, de la desdicha, de la locura, de la bondad y de la entrega. Escribir es un acto de generosidad excesiva y de plenitud delirante, por eso es tan exigente. $Y$ en ese aullido que es un relato o una novela se esconde un cuchillo, una navaja, un machete con el que debe cortarse el lector y sangrar. Y esa sangre nos purifica a todos, nos ayuda a celebrar, nos une en una comunión sagrada. (p. 72)

Pienso que lo mismo puede pensarse de la obra de Alonso Jiménez en relación con la pintura. Nunca he visto a Alonso pintando, pero mi fantasía es que pinta a una gran velocidad. Y la razón de su velocidad me parece tiene que ver, como en el texto de Mendoza, con que es una pintura que esconde un machete. Es una pintura que desgarra la piel, una pintura de vísceras por fuera. Quedarse contemplando los rostros desfigurados que pueblan la obra de Jiménez eventualmente produce un efecto siniestro, lo que Freud (1919/1989) nombraba el Umheimlich, una extraña familiaridad. Si uno se demora un poco más en el contacto cuerpo a cuerpo con esos rostros, eventualmente empieza a sentir que no es uno el que mira el cuadro, sino que es el cuadro el que lo mira a uno. Es el propio lienzo el que devuelve la mirada y ya no sabemos bien quién es espectador de quién. Pero si uno se demora aún más, aflora del propio cuadro ese machete que nos taja la piel y es allí que nos conectamos con lo más fundamental y profundo de su obra, es allí cuando su obra realmente nos interpela y ya no podemos abandonar la sala siendo los mismos.

Es también la obra de Jiménez un acto de generosidad. Es la bitácora de viaje de un artista conectado con realidades a las que no podemos tener acceso y que nos trae sus obras para que algo de ese mundo indomado pueda vibrar en nuestro cuerpo. El estudio de Jiménez, ubicado en el centro de Bogotá, es un termómetro de nuestra ciudad, una antena que logra captar las fibras más sensibles, las cuales atraviesan su cuerpo y ponen sus manos al trabajo con los materiales, trayéndonos un producto inédito que, por momentos - y allí lo siniestronos resulta extrañamente familiar, como si de alguna manera nuestra propia antena hubiera captado 
alguna vez algo de esa realidad, pero hubiéramos hecho todo lo posible para no saber nada de eso.

En ese punto convergen también los oficios del psicoanalista y el artista. J. A. Miller (2009) planteaba que tenemos que aprender a hablar "la lengua del Otro, para poder hacerle escuchar aquello de lo que no quiere saber nada" (p. 87). Es también ese un aspecto que lleva a Freud a sentirse tan fascinado por el arte, pues veía que algunos artistas lograban acceder a dimensiones a las que el psicoanálisis llegaba solamente después de un muy arduo esfuerzo. Nietzsche planteaba que el pensamiento sigue los pasos del artista, que siempre va un poco más adelante, goza (o padece) de una cierta anticipación. En Jiménez hay esa anticipación, oculta entre los trazos de los lienzos y entre los ojos observantes.

Con Alonso Jiménez hemos podido llevar a cabo un diálogo sobre lo que son las quimeras de nuestro tiempo, los nuevos faunos de nuestra época. Esto nos ha permitido ver que estos nuevos faunos no son más esos que relató Antonio Pigaffeta (1999) en 1536 en El primer viaje alrededor del mundo, en el que figuraban cerdos con ombligos en la espalda y a los que alude García Márquez en su discurso de recibimiento del premio Nobel. La obra de Jiménez, a mi modo de ver, es una exploración plástica que revela seres insospechados, de naturalezas múltiples, mutantes, enlazados con los pliegues de nuestros propios órganos. Por momentos nos interpela a nosotros mismos con una extrañeza insospechada; por momentos nos obliga a que no desconozcamos la bestia que somos.

Alonso Jiménez nos trae obras en las que figuran fragmentos de cuerpos, de rostros y que, en últimas, son fragmentos de una gran obra. Walter Benjamin planteaba que "para dilucidar cómo se han comportado los comensales no hay que verlos comer, hay que ver cómo dejaron la mesa una vez que partieron" (alusión de Forster, 2010, p. 124). Así, en estos fragmentos de la obra de Alonso podemos recorrer las zonas oscuras e indomadas de lo humano, recomponer ese banquete primordial del que desmiembran y desfloran las bestias con las que interactuaremos a lo largo de este año.

La invitación ahora es a adentrarnos en estas quimeras que durante el 2016 se expondrán en la portada de la revista Avances en Psicología Latinoamericana. Con suerte, aprovechando la generosidad de Alonso Jiménez de compartir un fragmento de su obra (las obras "Calígula" "Caín" y "Mujeres emberá taciturnas") con los lectores, podamos aprender cada uno algo de nuestra propia quimera.

\section{Referencias}

Danto, E. A. (2005). Freud's free clinics: Psychoanalysis and social justice, 1918-1938. New York: Columbia University Press.

Forster, R. (2010). Benjamin: una introducción. Buenos Aires: Cuadrata.

Freud, S. (1976). Lo ominoso. En J. L. Etcheverry (Trad.), Obras completas (vol. 17, pp. 216-251). Buenos Aires: Amorrortu.

Kundera, M. (2009). El gesto brutal del pintor: sobre Francis Bacon. Claves de Razón Práctica (192), 56-59.

Mendoza, M. (2013). La importancia de morir a tiempo. Bogotá: Planeta.

Miller, J. A. (2009). Perspectivas de política lacaniana. Freudiana (55), 85-92.

Pigafetta, A. (1999). El primer viaje alrededor del mundo. Barcelona: Biblioteca Grandes Viajeros.

Recalcati, M. (2006). Las tres estéticas de Lacan. Buenos Aires: Ediciones del Cifrado. 